\title{
Profile of MIBI Liquid Phase Radiopharmaceutical for Myocardial Imaging
}

\author{
I. Daruwati ${ }^{{ }^{\star}}$, M.E Sriyani ${ }^{1}$, N.K. Oekar ${ }^{1}$, A. Hanafiah ${ }^{2}$ and N. Zainuddin ${ }^{1}$ \\ ${ }^{I}$ Center for Applied Nuclear Science and Technology, National Nuclear Enegry Agency \\ Jl Tamansari No. 71, Bandung 40132, Indonesia \\ ${ }^{2}$ Indonesian College of Pharmacy (STFI), Jl. Soekarno Hatta No. 354, Bandung, Indonesia
}

\section{ARTICLE INFO}

Article history:

Received 04 October 2014

Received in revised form 10 November 2015

Accepted 25 November 2015

Keywords:

${ }^{99 \mathrm{~m}}$ Tc-MIBI

Stability of liquid phase kit

Myocardial imaging

\begin{abstract}
A B S T R A C T
The ${ }^{99 \mathrm{~m}}$ Tc-MIBI radiopharmaceutical has been used in nuclear medicine in Indonesia for myocardial imaging. BATAN researchers have mastered the technology to manufacture MIBI as a liophylized kit. A reformulation of MIBI radiopharmaceutical has been conducted to improve the stability of the kit especially in the liquid-phase kit. Basically, radiopharmaceuticals in liquid form are not different from the dry kit. However in the manufacturing of liquid-phase kit, lyophilization process was not done. To improve the stability of liquid kit, a reformulation of the components was conducted by using two separate vials (Formulation 2) and the characteristics were compared with the one-vial formulation (Formulation 1). The MIBI Formulation 2 consists of two vials, vial A containing $0.06 \mathrm{mg}$ of $\mathrm{SnCl}_{2} 2 \mathrm{H}_{2} \mathrm{O}$ and $2.6 \mathrm{mg}$ Sodium Citrate $2 \mathrm{H}_{2} \mathrm{O}$ and vial B containing $0.5 \mathrm{mg}$ of $\left[\mathrm{Cu}(\mathrm{MIBI})_{4}\right] \mathrm{BF}_{4}, 1 \mathrm{mg}$ of cysteine hydrochloride, and $20 \mathrm{mg}$ of mannitol. The purposes of this study were to determine the stability of two different formulations of MIBI as a liquid-phase kit, to compare their stability in different storage condition such as in refrigerator and freezer, and to compare the ratio of activities attained between target and nontarget organs after injection to animal model. As a diagnostic agent, MIBI was reconstituted with Technetium-99m as radionuclide tracer to ${ }^{99 \mathrm{~m}} \mathrm{Tc}$-MIBI labeled compound. The radiochemical purity of ${ }^{99 \mathrm{~m}} \mathrm{Tc}-\mathrm{MIBI}$ was determined by chromatography method using alumina thin-layer chromatography paper as the stationary phase and ethanol $95 \%$ as the mobile phase. The results showed MIBI Formulation 2 has a higher stability than Formulation 1. Formulation 2 also maintained a $96.68 \%$ radiochemical purity under 52-day storage and attained a target-to-nontarget activity ratio of 8.22 .
\end{abstract}

(C) 2016 Atom Indonesia. All rights reserved

\section{INTRODUCTION}

Radiopharmaceuticals are radioactive compounds used for the diagnosis and therapeutic treatment of human diseases [1,2]. In diagnostic applications, radiopharmaceuticals in the form of compounds that has been labeled with radioactive material are used as tracers; they are used to detect the interference and obstruction in organs and the existence of infections and tumors in the organs. Methoxyisobutylisonitrile (MIBI) is a ligand that was introduced in early $90 \mathrm{~s}$ and is used in the manufacture of radiopharmaceuticals for myocardial perfusion diagnosis and also for cancer detection

* Corresponding author.

E-mail address: isti@batan.go.id

DOI: http://dx.doi.org/10.17146/aij.2016.476
[3-5]. MIBI ligands are successfully synthesized at BATAN Bandung and have been utilized in the nuclear medicine at various hospitals in Indonesia such as the Hasan Sadikin Hospital in Bandung [6].

The ${ }^{99 \mathrm{~m}} \mathrm{Tc}$-MIBI radiopharmaceutical is a complex compound, a lipophilic agent with a positive charge which is easily taken up by myocardial cells through passive diffusion and localized in the mitochondria $[1,7]$. The ${ }^{99 \mathrm{~m}} \mathrm{Tc}$-MIBI complex is stabilized by six isonitrile ligand groups in the +1 oxidation state, forming a stable octahedral complex and it is stable in air and water $[3,8,9]$.

Therefore, the MIBI radiopharmaceutical is widely used for the diagnosis of myocardial perfusion in order to evaluate ischemic heart diseases and locate abnormal myocardium [9]. Several studies also developed this 
radiopharmaceutical to diagnose parathyroid gland disorders in cases of hyperthyroidism and breast cancer (oncology) [10-12]. In addition, the MIBI radiopharmaceutical can also be used for renal oncocytomas, diagnosis of metastatic cancer, detection of recurrent gliomas after radiotherapy, and evaluation of response to chemotherapy $[11,13]$.

The MIBI radiopharmaceutical was formulated in dry form by lyophilization process using a freeze dryer; the result has a longer shelf life than does the liquid form. The previous research was conducted in a single vial liquid from formula [6]. The aim of this reseach is to evaluate the stability of the two different formulations and to compare them. The first formula is a single vial containing both the ligand (MIBI) and the reducing agent $\left(\mathrm{SnCl}_{2}\right)$. The second formula separates the ligand and the reducing agent in different vials to improve stability during storage.

\section{EXPERIMENTAL METHODS}

\section{Labeling MIBI liquid phase kit formulation 1 and formulation 2 with technetium-99m}

For further work, two different MIBI radiopharmaceutical formulations were prepared. Henceforth, they will be referred to as Formulation 1 and Formulation 2.

The Formulation 1 of MIBI was dissolved with $0.5 \mathrm{~mL}$ of aquabidest and then stirred with a vortex mixer until homogeneous. Approximately 1.0 to $5.0 \mathrm{~mL}$ of $5-10 \mathrm{mCi}{ }^{99 \mathrm{~m}} \mathrm{Tc}$-pertechnetate (from PT INUKI) was added to the MIBI liquid kit, then restirred with a vortex mixer for a few seconds and heated in a boiling water bath for 10 minutes. The Formulation 2 of MIBI consisted of 2 vials (A and B). A precisely-measured $0.5 \mathrm{~mL}$ of A vial was inserted into $\mathrm{B}$ vial, then added with 1.0 to $5.0 \mathrm{~mL}$ of ${ }^{99 \mathrm{~m}} \mathrm{Tc}$-pertechnetate $(5-10 \mathrm{mCi})$ to the MIBI liquid kit, then stirred with a vortex for a few seconds and heated in a boiling water bath for 10 minutes [6]. The composition of formulation 1 and 2 are shown in Table 1.

Table 1. Formulation of MIBI liquid phase kit

\begin{tabular}{lllll}
\hline \multicolumn{2}{c}{ Formulation 1 } & \multicolumn{2}{c}{ Formulation 2 } \\
\hline$\left[\mathrm{Cu}(\mathrm{MIBI})_{4}\right] \mathrm{BF}_{4}$ & $0.5 \mathrm{mg}$ & Vial A \\
$\mathrm{SnCl}_{2} 2 \mathrm{H}_{2} \mathrm{O}$ & $0.06 \mathrm{mg}$ & $\mathrm{SnCl}_{2} 2 \mathrm{H}_{2} \mathrm{O}$ & $0.06 \mathrm{mg}$ \\
$\mathrm{Na}_{-}$-citrate. $2 \mathrm{H}_{2} \mathrm{O}$ & 2.6 & $\mathrm{mg}$ & Na-citrate. $2 \mathrm{H}_{2} \mathrm{O}$ & $2.6 \mathrm{mg}$ \\
Cisteine $\mathrm{HCl}$ & 1.0 & $\mathrm{mg}$ & Vial B \\
Mannitol & 20 & $\mathrm{mg}$ & {$\left[\mathrm{Cu}(\mathrm{MIBI})_{4}\right] \mathrm{BF}_{4}$} & $0.5 \mathrm{mg}$ \\
& & & Cisteine $\mathrm{HCl}$ & $1.0 \mathrm{mg}$ \\
& & & Mannitol & $20 \mathrm{mg}$ \\
\hline
\end{tabular}

\section{Radiochemical purity determination of MIBI liquid phase $[6,14]$}

The radiochemical purity of ${ }^{99 \mathrm{~m}} \mathrm{Tc}-\mathrm{MIBI}$ was determined by paper chromatography. A preciselymeasured $5 \mu \mathrm{L}$ of ${ }^{99 \mathrm{~m}} \mathrm{Tc}-\mathrm{MIBI}$ was spotted on alumina thin layer chromatography paper (TLC- $\mathrm{Al}_{2} \mathrm{O}_{3}$ ) as the stationary phase, then eluted with absolute ethanol as the mobile phase. Alumina TLC paper sheets were dried at $80^{\circ} \mathrm{C}$, then cut after each $1 \mathrm{~cm}$ and counted using a single-channel gamma counter. The purity of ${ }^{99 \mathrm{~m}} \mathrm{Tc}$-MIBI was calculated based on the separation of impurities with different retention factors (RF), namely $\mathrm{RF}=0.6-0.7\left({ }^{99 \mathrm{~m}} \mathrm{TcO}_{4}\right) ; \mathrm{RF}=0.0\left({ }^{99 \mathrm{~m}} \mathrm{TcO}_{2}\right)$ and $\left.\mathrm{RF}=0.8-1.0{ }^{(99 \mathrm{~m}} \mathrm{Tc}-\mathrm{MIBI}\right)[6]$.

\section{Stability of the MIBI liquid phase kits under storage}

MIBI Liquid Kit formulations 1 and 2 were stored in freezer and their stability was periodically tested. Their stability was determined by labeling techniques with technetium-99m, and then the radiochemical purity of ${ }^{99 \mathrm{~m}} \mathrm{Tc}-\mathrm{MIBI}$ was calculated. The percentage of ${ }^{99 \mathrm{~m}} \mathrm{Tc}-\mathrm{MIBI}$ radiochemical purity must fulfill the requirements of a good radiopharmaceutical (>90\%) [15].

\section{Stability of MIBI liquid phase kit at room temperature}

The stability of MIBI liquid phase kit was tested by labeling and radiochemical purity determination. The ${ }^{99 \mathrm{~m}} \mathrm{Tc}-\mathrm{MIBI}$ radiopharmaceuticals were stored at room temperature for 4 hours and were tested every one hour.

\section{Determination of ratio target and non-target in animal model}

A precisely-measured $200 \mu \mathrm{Ci} / 200 \mu \mathrm{L}$ ${ }^{99 \mathrm{~m}}$ Tc-MIBI radiopharmaceutical with high radiochemical purity (>90\%) was intravenously injected through the tail of Wistar rats. The animal models were killed at 30 minutes after injection, and then the organs such as heart, liver, kidneys and lungs were collected and counted using a single-channel analyzer. The ratio between activities attained in target organs and in non-target organs was calculated. 


\section{RESULTS AND DISCUSSION}

MIBI liquid kits were produced in two different formulas, namely Formulation 1 in the single vial and Formulation 2 in two vials (vials A and B), as shown in Fig. 1. The separation of tin chloride in the different vial is to prevent the reaction of tin chloride with other compounds, especially in liquid form.

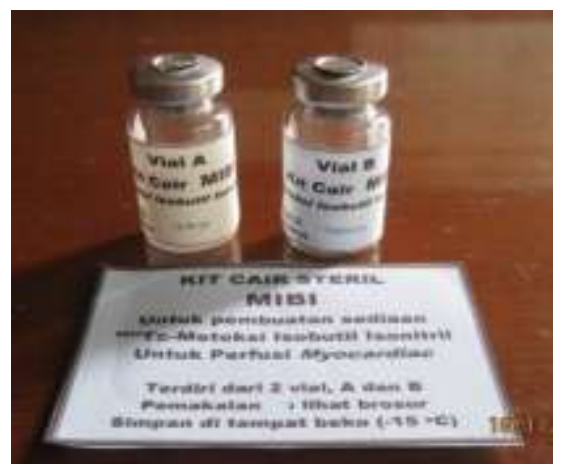

Fig. 1. MIBI Liquid Phase Kit (Formulation 2).

Basically, the manufacturing process of liquid phase kit is similar to dry kit. All the activities carried out in aseptic conditions in a sterile room, without the lyophilization process. The final products of liquid kit were stored in a lower temperature such as refrigerator $\left(4^{\circ} \mathrm{C}\right)$ and freezer $\left(<0^{\circ} \mathrm{C}\right)$.

As shown in Fig. 2, the stability of liquid kit MIBI Formulation 1 was tested by storage in a refrigerator $\left(4^{\circ} \mathrm{C}\right)$. The results showed that radiochemical purity of ${ }^{99 \mathrm{~m}} \mathrm{Tc}-\mathrm{MIBI}$ was decreased to $65 \%$ on day 23 .

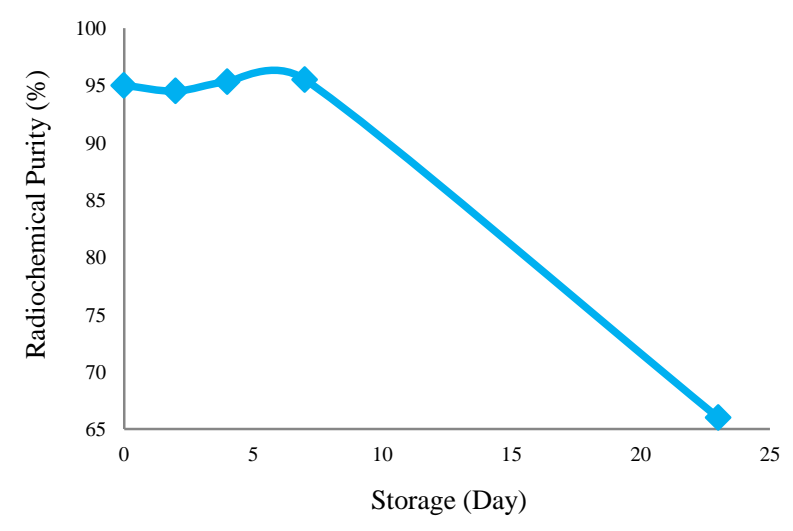

Fig. 2. Stability of liquid kit MIBI Formulation 1 in the refrigerator $\left(4^{\circ} \mathrm{C}\right)$

As shown in Fig. 3, liquid kit MIBI Formulation 2 showed higher stability than Formulation 1 until day 52 under the storage in the freezer; Formulation 2 maintains a radiochemical purity of $96.68 \%$. Formulation 1's radiochemical purity decreased to $50.54 \%$ after 17 days of storage.
Thus, it can be concluded that Formulation 2, which separates its tin chloride in a different vial, can prevent the reaction between the tin chloride and other components, because tin chloride as a reducing agents is very sensitive to oxidation [15].

$$
\begin{aligned}
& \mathrm{TcO}_{4}^{-}+\text {Citrate } \stackrel{\mathrm{Sn}^{2+}}{\longrightarrow} \text { Tc-Citrate } \\
& {\left[\mathrm{Cu}(\mathrm{I})(\mathrm{MIBI})_{4}\right]^{+}+\mathrm{Tc}-\mathrm{Citrate} \stackrel{\text { heat }}{\longrightarrow}\left[\mathrm{Tc}(\mathrm{I})(\mathrm{MIBI})_{6}\right]^{+}}
\end{aligned}
$$

The reaction of MIBI complex based on ligand exchange is stated in equations (1) and (2). Cysteine and stannous chloride are reducing agents. Manitol is a bulking agent and forms a weak complex with reduced technetium. Under heating process, copperMIBI complex is broken and it releases a MIBI ligand with an isonitrile group. The MIBI ligands displace citrate from the preformed ${ }^{99 \mathrm{~m}} \mathrm{Tc}$-citrate intermediate to form ${ }^{99 \mathrm{~m}} \mathrm{Tc}$-sestamibi. After the ${ }^{99 \mathrm{~m}}$ Tc-MIBI complex was formed, the ${ }^{99 \mathrm{~m}} \mathrm{Tc}$-citrate no longer remains and its radiochemical impurity cannot be determined.

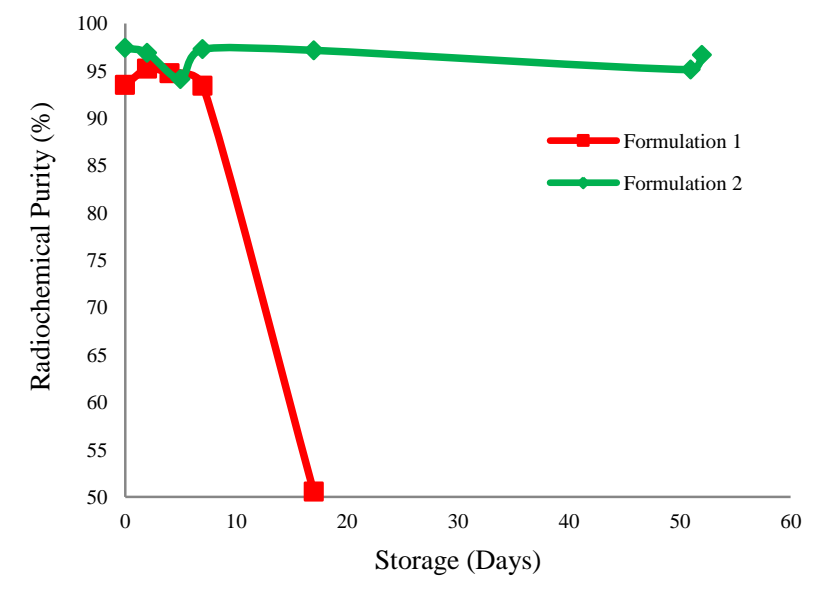

Fig. 3. Stability of liquid kit MIBI Formulation 1 and Formulation 2 which storage in the Freezer $\left(<0^{\circ} \mathrm{C}\right)$.

Figure 4 shows the effect of the final volume of ${ }^{99 \mathrm{~m}} \mathrm{Tc}-\mathrm{MIBI}$ on its radiochemical purity. The maximum volume actually used for labeling liquid kit was $5 \mathrm{~mL}$ with a radiochemical purity of more than $90 \%$. Radiation causes decomposition of water, a main ingredient of most radiopharmaceuticals, leading to the production of reactive hydrogen atoms and hydroxyl radicals, hydrated electrons, hydrogen, hydrogen ions, and hydrogen peroxide. The last substance mentioned is formed in the presence of oxygen radicals, originating from the radiolytic decomposition of dissolved oxygen. Many radiopharmaceuticals show improved stability if oxygen is not present [14]. 


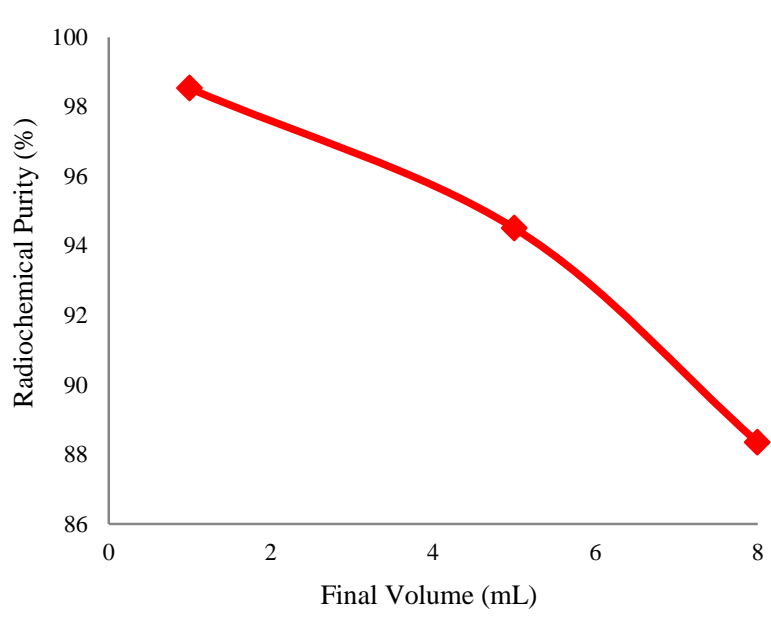

Fig. 4. Effect of final volume to radiochemical purity of ${ }^{99 \mathrm{~m}} \mathrm{Tc}-$ MIBI Formulation 2.

After reconstitution, ${ }^{99 \mathrm{~m}} \mathrm{Tc}-\mathrm{MIBI}$ from Formulation 2 showed good stability at room temperature until 4 hours with a radiochemical purity staying more than 90\% (95.73\%) (Fig. 5). It coresponds with previous research by Nurlaila, which found that 4 hours after reconstitution, the radiochemical purity was still high (>95\%) [6]. High radiochemical purity will give an overview to practitioners in hospitals that ${ }^{99 \mathrm{~m}} \mathrm{Tc}$-MIBI could be given to the patient until 4 hour of reconstitution.

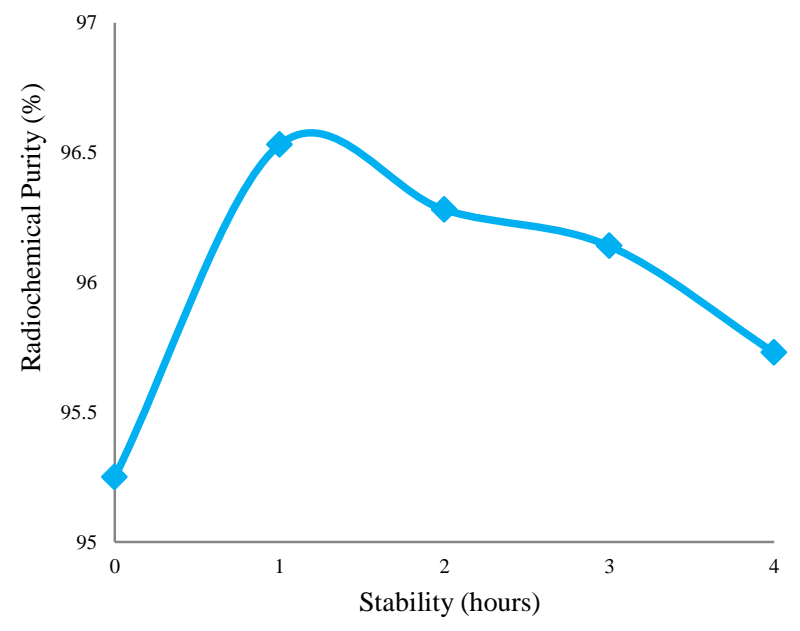

Fig. 5. Stability of ${ }^{99 \mathrm{~m}}$ Tc-MIBI Formulation 2 in the room temperature $\left(25^{\circ} \mathrm{C}\right)$.

Myocardial imaging is performed by intravenous injection at rest and under stress condition. In this study, scanning of ${ }^{99 \mathrm{~m}} \mathrm{Tc}-\mathrm{MIBI}$ is performed at rest condition as early as $30 \mathrm{~min}$ after injection using Wistar Rat (Fig. 6). After intravenous administration, ${ }^{99 \mathrm{~m}}$ Tc-MIBI is rapidly cleared from the blood, with only $8 \%$ of the administered activity remains in the circulation 5 min after injection [1].
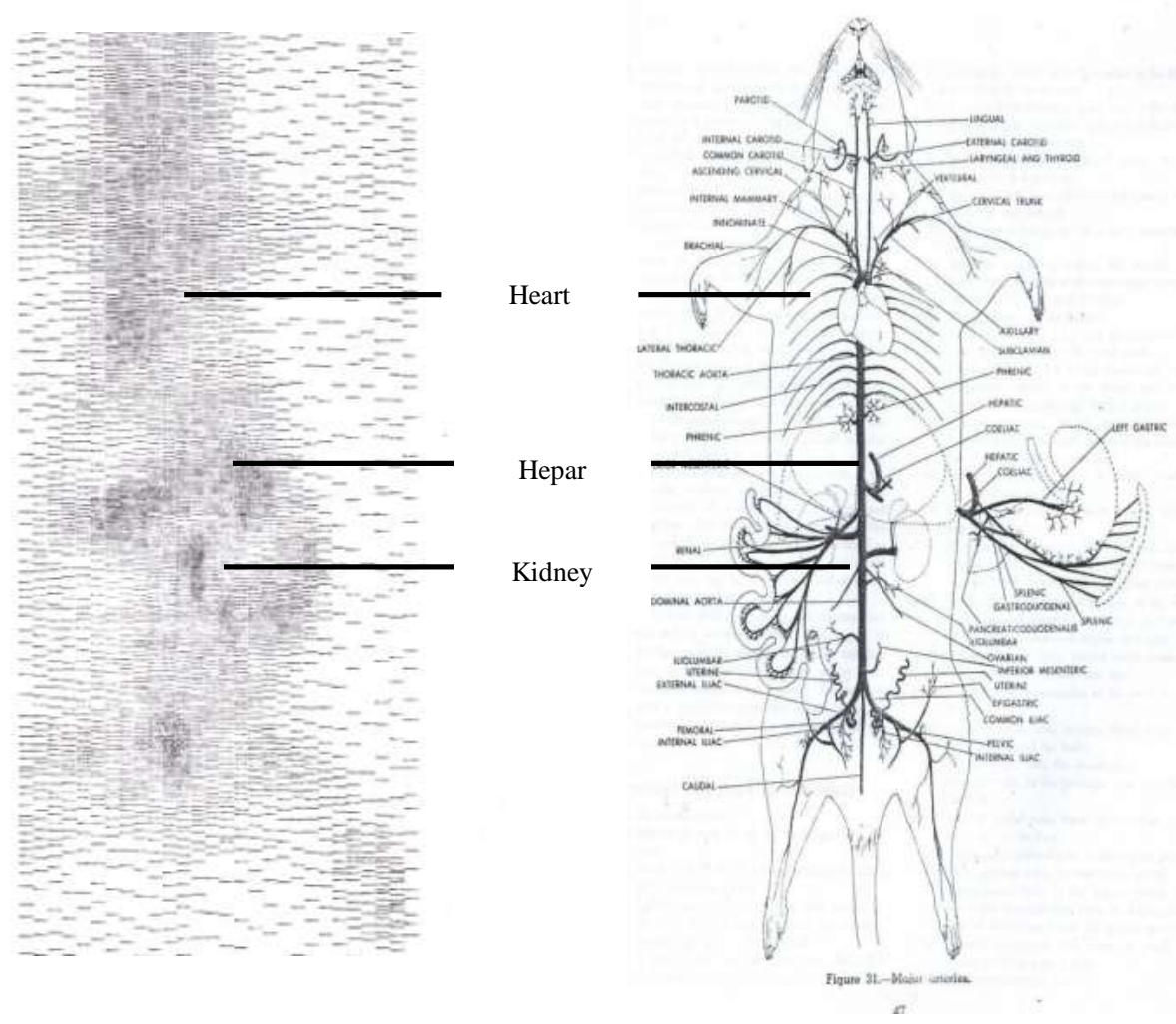

Fig. 6. Scanning of ${ }^{99 \mathrm{~m}}$ Tc-MIBI 30 minutes after iv injection of ${ }^{99 \mathrm{~m}} \mathrm{Tc}-\mathrm{MIBI}$ using Wistar rat. 
The scanning showed high accumulation of ${ }^{99 \mathrm{~m}} \mathrm{Tc}-\mathrm{MIBI}$ at heart, liver, and kidney. Then, accumulation of ${ }^{99 \mathrm{~m}} \mathrm{Tc}-\mathrm{MIBI}$ occurs by biodistribution. An ideal radiopharmaceutical for imaging should attain a target-to-nontarget activity ratio of greater than 3.0. The tracer is excreted through both the hepatobiliary system $(33 \%$ at 48 hours) and the urine (27\% at 24 hours), and its biological half-life in the myocardium is approximately 7 hours [1].

Figure 7 shows heart-to-liver activity ratio of 5.46 and 8.22 for Formulation 1 and Formulation 2, respectively. This suggests that Formulation 2 gives a higher ratio than Formulation 1. Figure 8 shows that Formulation 2 attains lung- and kidney-to-heart ratios of 4.32 and 0.99 respectively. This result showed higher ratios than other -research using nitrido complex ${ }^{99 \mathrm{~m}} \mathrm{TcN}-\mathrm{MIBI}$ [16].

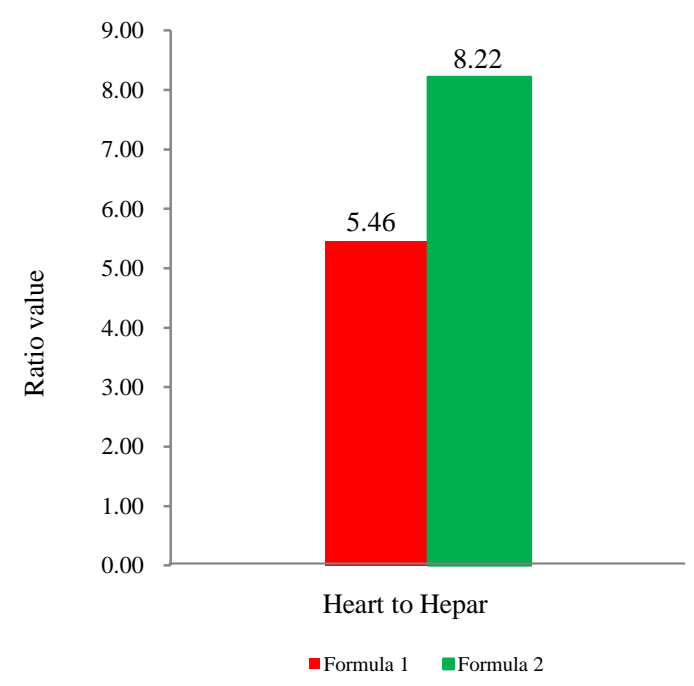

Fig. 7. Heart to hepar ratio, 30 minutes after iv injection of ${ }^{99 \mathrm{~m}}$ Tc-MIBI using Wistar rat.

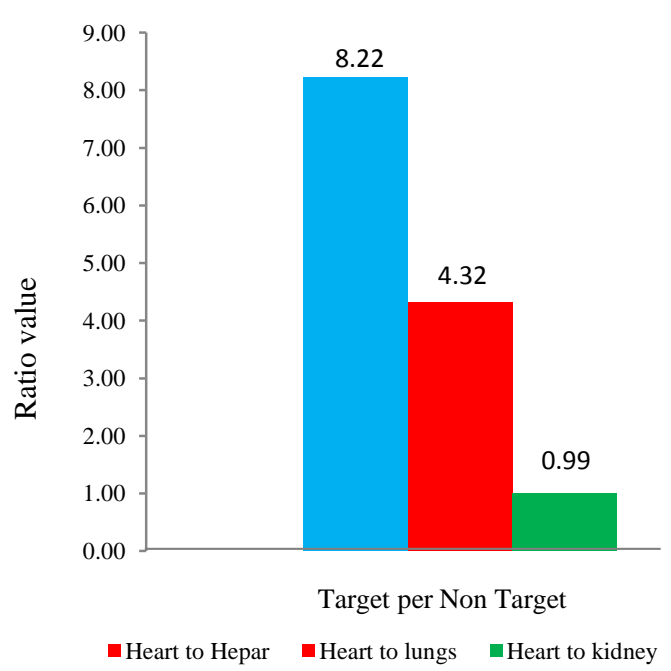

Fig. 8. Target to non target ratio, 30 minutes after iv injection of ${ }^{99 \mathrm{~m}}$ Tc-MIBI Formulation 2 to animal model.

\section{CONCLUSION}

The two-vial formulation (Formulation 2) of MIBI liquid kit exhibits a higher stability than the one-vial Formulation 1. The Formulation 2 liquid kit remains stable until 52 days of storage inside a freezer and for 4 hours after reconstitution, and with a maximum final volume of $5 \mathrm{~mL}$ its radiochemical purity stay greater than $90 \%$. This result showed higher target-to-nontarget ratios than using nitrido complex ${ }^{99 \mathrm{~m}} \mathrm{TcN}-\mathrm{MIBI}$. In the next step to final product, this research will countinue with the development of dry and sterile MIBI kit with lyophilization process.

\section{ACKNOWLEDGMENT}

Our sincere thanks especially to Mr. Iswahyudi, Mr. Epy Isabella, Mrs. Yetti Suryati, Prina Puspa Kania, and Teguh Hafiz AW. This research is part of the research activity carried out with funds from PKPP, the Ministry of Research and Technology of Indonesia.

\section{REFERENCES}

1. F. Orsini, A. Lorenzoni, P.A. Erba et al., Radiopharmaceuticals for Single Photon Emission Imaging and for Therapy, Nuclear Oncology, in: Pathophysiology and Clinical Applications, W. Strauss et al (Ed). Springer, New York (2013) 21.

DOI:10.1007/978-0-387-48894-3_2.

2. S. Soenarjo, J. Radioisotopes and Radio pharmaceuticals 17 (2014) 15. (in Indonesian)

3. R. Mikołajczak and P. Garnuszek, Radiopharmaceuticals in cardiology, Nuclear Medicine Review 15 (2012) 39.

4. Barros, P.P. De, Metello et al., Radiol. Bras. 48 (2015) 305.

5. D. Seker, G. Seker, E. Ozturk et al., J. Breast Cancer 15 (2012) 252.

DOI:10.4048/jbc.2012. 15.2.252 PMCID: PMC3395752.

6. Z. Nurlaila and I. Daruwati, Atom Indonesia 34 (2008) 35.

7. S. Matsuo, K. Nakajima and S. Kinuya, Asia Oceania Journal of Nuclear Medicine and Biology 1 (2013) 39.

8. J. Ponto, UNM Coll. Pharm. 16 (2012) 1.

9. J. Bucerius, H. Ahmadzadehfar and H.J. Biersack, ${ }^{99 \mathrm{~m}}$ Tc-Sestamibi Clinical 
Application, Springer, Berlin (2012) 1. DOI:10.1007/978-3-642-0423301.

10. E.M. Ryhänen, J. Schildt, I. Heiskanen et al., Int. J. Mol. Imaging 2015 (2015) 1. DOI: $10.1155 / 2015 / 391625$

11. M.M. Cona, P. de Witte, A. Verbruggen et al., World J. Methodol. 3 (2013) 45.

12. L.R. Greene and D. Wilkinson. J. Med. Radiat. Sci. 62 (2015) 54.

13. M. Gorin, S.P. Rowe, A.S. Baras et al. Eur. Urol. 69 (2016) 413.

DOI:10.1016/j.eururo.2015.08.056.
14. Anonymous. The $35^{\text {th }}$ United State Pharmacopoeia - the $30^{\text {th }}$ Edition of National Formulary, The United State Pharmacopoeia Convention (2012).

15. I. Zolle, Technetium-99m Pharmaceuticals: Preparation and Quality Control in Nuclear Medicine, Department of Medicinal/ Pharmaceutical Chemistry University of Vienna (2007) 59.

16. X.Zh. Zhang, X.B. Wang, F. Jia et al., J. Labelled Compounds and Radiopharmaceuticals 45 (2002) 1029. DOI: $10.1002 / \mathrm{jlcr} .621$. 